\title{
INOVANDO O ARTESANATO COM ESCAMAS DE PEIXES: TINGIMENTO NATURAL E MARCA.
}

\section{INNOVATING HANDICRAFT WITH FISH SCALES: NATURAL DYE AND BRAND.}

\author{
Weruska de Melo Costa ${ }^{1}$ \\ Mariana Cristina Mourão Veiga ${ }^{2}$ \\ Juliana Maria Aderaldo Vidal ${ }^{3}$ \\ Maria Alice Rocha ${ }^{4}$
}

\begin{abstract}
RESUMO: Este trabalho demonstrou como os extratos vegetais atuam na coloração e na fixação da cor em escamas de peixe utilizadas por comunidades de pescadoras na produção de artesanato e adequar práticas em design e marca. O método de investigação adotado foi a pesquisa laboratorial, a partir de diferentes concentrações de chás e de participação da comunidade no desenvolvimento e escolha da marca. As oficinas possibilitaram o uso dos materiais para a produção, das técnicas artesanais e da relação local, evidenciando o potencial para se promover a sustentabilidade ambiental e a geração de renda. Os resultados demonstraram que a intervenção do design na produção artesanal valoriza a riqueza dos resíduos pesqueiros. As flores de escamas tingidas foram aplicadas ao artesanato e inseridas no contexto local. Através da marca, a comunidade poderá adquirir visibilidade e incorporação de uma nova atividade em sua cultura.
\end{abstract}

Palavras chave: Design, Resíduos, Coloração.

ABSTRACT: This work is the result from use vegetal extracts to dye in fixing of color on fish scales used by fishers community in producing handicraft and tailor practices in design

\footnotetext{
${ }^{1}$ Universidade Federal Rural de Pernambuco - weruskademelo@ gmail.com

${ }^{2}$ Universidade Federal Rural de Pernambuco - mariana.veiga_83@yahoo.com.br

${ }^{3}$ Unidade Acadêmica de Serra Talhada - julymav@yahoo.com.br

${ }^{4}$ Universidade Federal Rural de Pernambuco - modalice.br@gmail.com
} 
and brand. The research method adopted was laboratory research, from different infusions and community participation in development and brand choice. The workshops allowed the use of materials for production, craft techniques and the local relationship, showing the potential to promoting environmental sustainability and income generation. The results showed that the intervention design in craft production values the wealth of fish waste. The flowers dyed scales were applied to craft and incorporated in the local context. By brand, the community may acquire visibility and incorporation of a new activity in their culture.

Keywords: Design, Waste, Coloring.

\section{INTRODUÇÃO}

Existem diversas atividades econômicas que causam impactos ao meio ambiente, entre elas, destaca-se a pesca. Atividade milenar que, ainda hoje, é de considerável importância em todo o mundo, como fonte geradora de alimentos, emprego e renda para vários segmentos econômicos (BENTO; BEMVENUTI, 2008).

Segundo o Ministério da Pesca e Aquicultura (MPA, 2013) a atividade pesqueira pode ser classificada, de acordo com sua finalidade, em artesanal, industrial e amadora. Ainda segundo o MPA (2013), o Brasil produz aproximadamente 1 milhão e 240 mil toneladas de pescado por ano, sendo que cerca de $45 \%$ dessa produção é da pesca artesanal. Contudo, há um problema referente a esta atividade que está na forma de destinação dos resíduos pesqueiros, já que estes possuem alta carga de matéria orgânica, que, se mal gerenciados, podem afetar as características do solo e dos recursos hídricos.

A atividade pesqueira é uma atividade sujeita a uma série de efeitos internos e externos, cuja correlação ainda hoje não é bem conhecida. Assim, o ambiente aquático e os seres vivos que o habitam sofrem influências de oscilações climáticas e antrópicas, tornando difíceis as previsões em termos de pesca (DIAS-NETO; DORNELLES, 1996). No caso da pesca continental, dentre as causas de declínio da produção, incluem-se: poluição ambiental, uso de insumos aplicados à agricultura, construção de barragens, aterros e canalização de rios 
e córregos. Infelizmente, muitos destes instrumentos que vem sendo utilizados correntemente para mitigar esses problemas estão causando novos prejuízos para a manutenção dos estoques pesqueiros, por como exemplo, o repovoamento de reservatórios com espécies exóticas de peixes (PETRERE, 1994).

O aumento do cultivo de peixes também intensifica a geração de resíduos do pescado cultivado, determinando a necessidade de alternativas sustentáveis, como seu reaproveitamento, que contribuem para o bem social, econômico e ambiental (SEBRAE, 2010).

Os resíduos da pesca e aquicultura oriundos do beneficiamento ou processamento de pescados são constituídos por cabeças, vísceras, nadadeiras, peles, escamas, espinhos. Uma importante finalidade destes resíduos é seu reaproveitamento para a fabricação de farinha de peixe (MACHADO, 1984), que é utilizada na produção da ração para animais, proporcionando o aproveitamento integral e sustentável do pescado. Existem muitas alternativas sustentáveis de reaproveitamento dos resíduos da pesca e aquicultura, porém nem sempre é o caminho utilizado pelos pescadores, que não os destinam à reciclagem, e sim inapropriadamente, em rios, estuários, mar, ou aterros sanitários. Estas opções de descarte podem causar diversos impactos ambientais, sociais, e até mesmo econômicos. Em muitos casos, esta destinação inadequada dos resíduos de pescado pode ser relacionada à necessidade de melhores informações voltadas para educação e conscientização sobre a área de resíduos (SEBRAE, 2010).

A degradação ambiental e poluição foram avaliadas como consequências inevitáveis do progresso, a conservação da qualidade de vida e a preservação ambiental caminhavam de forma contrária (SOUZA, 2003). Os impactos causados pelas atividades antrópicas exercidas sobre o meio ambiente eram praticamente desconsiderados, assim como as contínuas emissões de poluentes para o ar e a água. Entretanto, a magnitude e proporção atingida pela miséria e poluição começaram a chamar a atenção da sociedade, fazendo com que ela repensasse o seu desenvolvimento, conciliando o desenvolvimento econômico e social com a qualidade ambiental (MILLANI, 2007). 
A destinação correta dos resíduos da Pesca e Aquicultura, bem como o aproveitamento integral do pescado, tanto da pesca extrativa quanto da aquicultura figura atualmente entre os principais desafios de suas cadeias produtivas, principalmente quando nos referimos à sustentabilidade destas atividades (SEBRAE, 2010). Atualmente uma elevada procura acontece para obtenção de resíduos do pescado, escamas e couro de peixes com objetivo de confeccionar peças artesanais ecologicamente corretas.

Segundo a Norma Brasileira (NBR) 10.004 (ABNT, 2004) os resíduos de pescado possuem duas classificações:

- Classe I: Perigosos - Apresentam propriedades físicas, químicas ou infectocontagiosas, que oferecem risco à saúde pública e ao meio ambiente, como resíduos de pescado contaminados;

- Classe II: Não Inertes - Possuem propriedades como: combustibilidade, biodegradabilidade ou solubilidade em água, como resíduos de pescado não contaminados.

Os resíduos de Classe II são aqueles com maior potencial para a reciclagem. A destinação correta dos resíduos da Pesca, bem como o aproveitamento integral do pescado, tanto da Pesca Extrativa quanto da Aquicultura, figura atualmente entre os principais desafios de suas cadeias produtivas, principalmente quando se refere à sustentabilidade destas atividades. Existem muitas alternativas sustentáveis de reaproveitamento dos resíduos pesqueiros, que podem, ainda, ser reutilizados para fabricação de subprodutos, tais como, linguiças, hambúrguer de peixe (fishburguers), caldos e iscas de peixe. Adubos orgânicos, assim como produtos artesanais também podem ser originados a partir dos resíduos pesqueiros (SEBRAE, 2010).

A gestão do resíduo de pescado exige planejamento e tecnologias adequadas, uma vez que os aspectos ambientais, legais e econômicos são interdependentes e precisam ser geridos com eficiência, pois este setor apresenta enorme fragilidade e recebe influência de fatores naturais de difícil modelagem como fenômenos climáticos e oceanográficos que são limitantes ao aumento e estabilidade da produção (MARTINS, 2011).

A partir dos anos 70, desenvolveram-se avanços tecnológicos com relação ao tratamento de resíduos sólidos na indústria pesqueira. A viabilidade de se elaborar 
subprodutos de pescado relaciona-se diretamente à qualidade dos resíduos gerados nas linhas de produção (MELO, 2007). Portanto, não só a indústria de pescado mais os pescadores que realizam a pesca artesanal possuem matéria-prima para o processamento de resíduos gerando novos produtos, bem aceitos no mercado.

Este trabalho teve como objetivo agregar de valor ao artesanato das comunidades pesqueiras através do tingimento das escamas de peixe com utilização de corantes naturais e artificiais através de técnicas de aplicação de corantes vegetais e desenvolver de uma marca para as artesãs utilizarem no produto.

\section{MATERIAL E MÉTODOS}

O projeto ComuniArte teve como principal objetivo, difundir nas comunidades de pescadores o aproveitamento de resíduos de pescado, utilizando metodologias distintas através de oficinas e ajudando na melhoria de renda da população local através de aulas presenciais, expositivas e práticas utilizando cartilha própria para o curso. Os cursos e oficinas foram ministrados nas comunidades de Serra Talhada: Açude Saco I, somente com escamas de tilápia (Oreochromis niloticus).

Na comunidade de Porto de Jatobá: Colônia dos Pescadores Z-33, Município de Abreu e Lima, Região Metropolitana Norte do Recife e tem como principal bacia hidrográfica o rio Timbó e na comunidade de Barra de Sirinhaém: Colônia de Pescadores Z-10. Houve o aproveitamento de escamas de peixes marinhos de Corvina (Micropogonias furnieri), Anchova (Pomatomus saltator), Cioba (Lutjanus analis), Pescada Amarela (Cynoscion spp) e Badejo (Mycteroperca spp) em ambas as comunidades.

As escamas foram beneficiadas por cada comunidade. $\mathrm{O}$ material coletado passou por um processo de beneficiamento com dois ciclos de lavagem em água corrente a fim de descongelar as escamas e separar os resíduos cárneos. Para desodorizar e desinfetar foi utilizada uma solução de hipoclorito de sódio $(2,0 \%$ p/p) e água durante um período de 12 horas, numa proporção de $100 \mathrm{~mL}$ de hipoclorito de sódio (2,0\%p/p) para $1000 \mathrm{~mL}$ de água, 
com mais dois ciclos de lavagens. Posteriormente, as escamas foram lavadas em água corrente para remoção dos resíduos químicos seguida de filtração (SANTOS et al, 2012).

\section{TINGIMENTO NATURAL}

Inicialmente foi realizada uma pesquisa bibliográfica e verificou-se que não existia procedimento metodológico para coloração das escamas de peixes, sendo assim, foi verificado o procedimento do tingimento de tecidos, sendo base para um novo protocolo nesta metodologia.

Para o tingimento natural, realizou-se uma listagem de vegetais que contêm corantes, porém a maioria apresentou dificuldade de aquisição e certas plantas apresentaram custo elevado. Para realização da produção, foram utilizadas plantas naturais selecionadas e adquiridas no Mercado de São José no centro do Recife. A escolha foi realizada pelas vantagens apresentadas, ou seja, maior facilidade de compra e baixo custo.

Os vegetais selecionados foram: chá verde, angico, carqueja, sene, amora miúra, barbatimão, chá de casca de cebola (Figura 1).
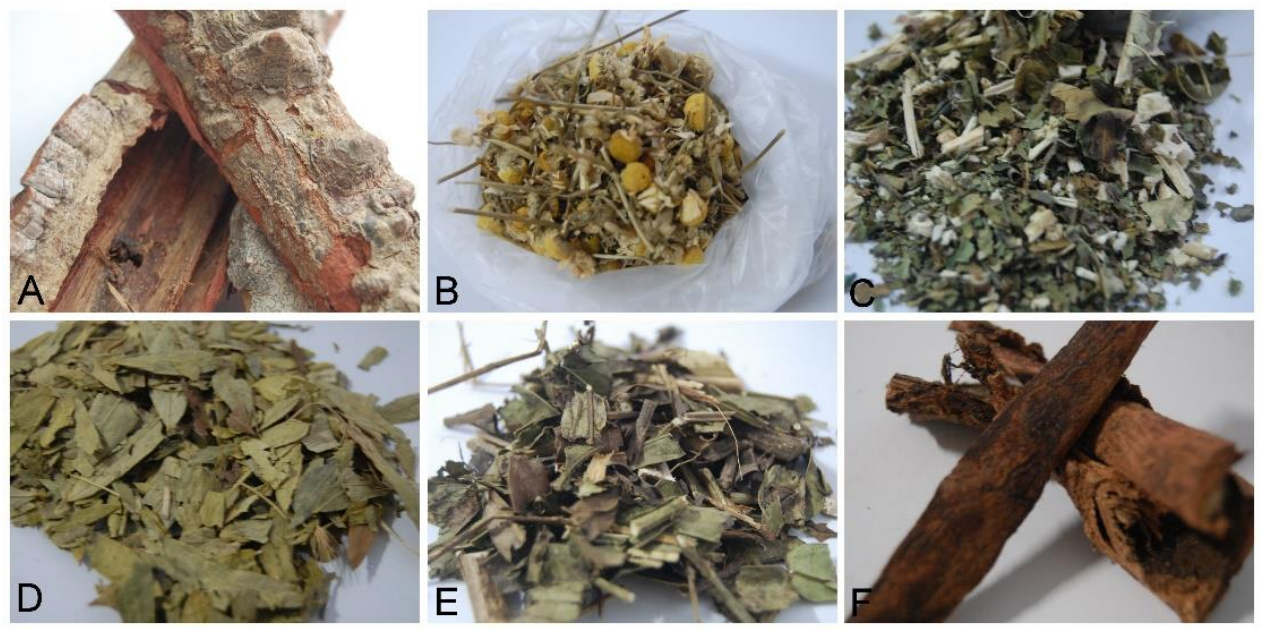

Figura 1): Exemplo de corantes naturais: a) Angico; b) Carqueja; c) Chá verde; d) Sene; e) Amora Miúra e f) Barbatimão. Foto: Mariana Veiga. 
Separou-se um recipiente com $1000 \mathrm{ml}$ de água que foi submetida à fervura, após o ponto de ebulição acrescentou-se o corante criando a infusão permanecendo por 10 minutos em aquecimento (Figura 2).
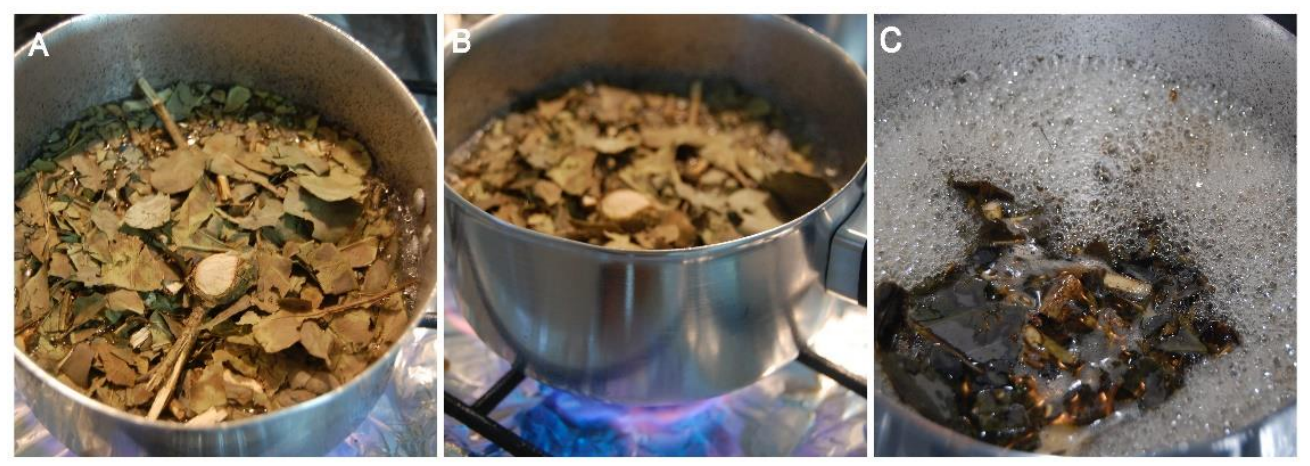

Figura 2): Infusão: a) Aplicação do corante natural; b) Aquecimento e c) Infusão.

Foto: Mariana Veiga.

Em cada recipiente contendo escamas de peixes aplicou-se a infusão e em seguida foi acrescentado $100 \mathrm{ml}$ de álcool $70 \%$ para fixação da coloração. Essa metodologia foi realizada para cada corante natural que permaneceu em repouso por 03 dias e observando se todas as escamas estavam recebendo coloração de forma homogênea, ou seja, sempre que necessário agitou-se a solução para manter a homogeneidade. Após o período de repouso as escamas foram colocadas para secagem de forma alternada à sombra e ao sol.

Nesta metodologia foram realizadas três repetições para certificar a cor desejada.

\section{RESULTADOS}

Os resultados demonstraram que a aplicação de diferentes corantes naturais foi positiva, pois apesar da variação nas cores, a tonalidade será aplicada a partir da quantidade de corante utilizada. Identificou-se que no chá verde, chá de carqueja a coloração foi modificada conforme o corante utilizado, ou seja, na metodologia foram usadas folhas naturais e chás de saquinhos industrializados comercializadas em sachês no qual foram submetidas à mesma metodologia. As características comuns a cada espécie vegetal estão 
representadas na Tabela 1, que evidenciam a época de colheita e sua facilidade de encontrar com a quantidade utilizada por litro de infusão, demonstrando valorização do produto natural que não agride o ambiente.

Tabela 1): Descrição e características dos vegetais utilizados como corantes:

\section{Parte}

\begin{tabular}{|c|c|c|c|c|c|c|}
\hline Planta & Nome Científico & $\begin{array}{l}\text { Época da } \\
\text { Colheita }\end{array}$ & $\begin{array}{l}\text { Onde } \\
\text { Encontrar }\end{array}$ & $\begin{array}{l}\text { para } \\
\text { extração }\end{array}$ & Cor & $Q t d(g)$ \\
\hline $\begin{array}{l}\text { Amora } \\
\text { Miúra }\end{array}$ & Morus nigra & Primavera & Cultivada & Folhas & Verde & $35 \mathrm{~g}$ \\
\hline Angico & $\begin{array}{l}\text { Parapiptadenia } \\
\text { rigida }\end{array}$ & Julho/Julho & Cultivada & Casca & Marrom & $45 \mathrm{~g}$ \\
\hline Barbatimão & $\begin{array}{l}\text { Stryphnodendrun } \\
\text { barbadetiman }\end{array}$ & $\begin{array}{l}\text { Julho/Agosto/ } \\
\text { Setembro }\end{array}$ & Espontâneo & Casca & $\begin{array}{l}\text { Marrom } \\
\text { avermelhado }\end{array}$ & $45 \mathrm{~g}$ \\
\hline Сагquеја & $\begin{array}{l}\text { Baccharis trimera } \\
\text { L. }\end{array}$ & Ano todo & Cultivada & lhas & Verde & $30 \mathrm{~g}$ \\
\hline Sene & $\begin{array}{l}\text { Cassia } \\
\text { angustifolia }\end{array}$ & Primavera & Cultivada & Folhas & $\begin{array}{l}\text { Marrom } \\
\text { escuro }\end{array}$ & $25 \mathrm{~g}$ \\
\hline Cebola & Allium cepa & Outono/inverno & Cultivada & Casca & $\begin{array}{l}\text { Marrom } \\
\text { claro/escuro }\end{array}$ & 02 \\
\hline Chá verde & Camellia sinensis & Primavera/verão & Cultivada & Folhas & Verde & $25 \mathrm{~g}$ \\
\hline
\end{tabular}

O chá de carqueja apresentou escamas alternadas (verde clara e escura) ao utilizar sachê e escamas verde-escuras quando usadas folhas. Amora miúra, angico e barbatimão (Figura 3), representaram o grupo com coloração forte e adequada para o uso em diversas peças, incluindo peças que podem estar em contato com a pele (brincos e colares), ou tecidos por 
não apresentarem descoloração com o tempo. As peças foram submetidas a uso e permanência ao sol e não apresentaram diferenças em sua coloração.

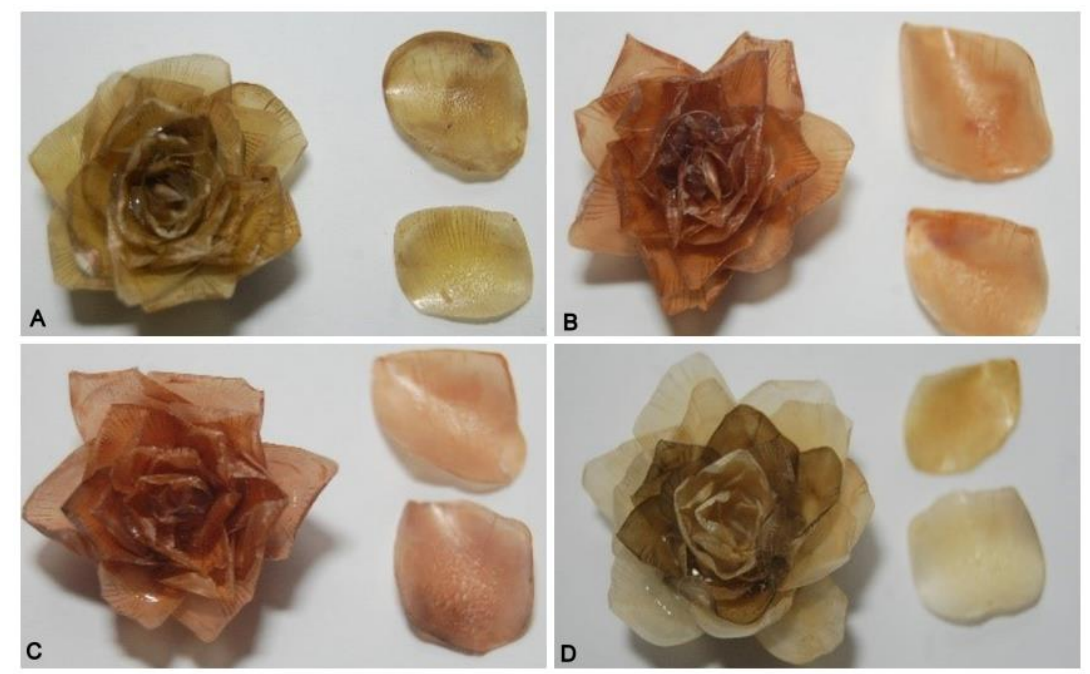

Figura 3): Resultado das flores de escama com corantes naturais.

a) Amora Miúra; b) Angico; c) Barbatimão; d) Carqueja. Foto: Mariana Veiga.

Os corantes naturais: sene cebola e chá verde não apresentaram alteração na coloração (Figura 4). O chá verde obteve a coloração esverdeada ao usar folhas e coloração marrom na utilização de sachês devido à presença de potássio (14mg em cada sachê) que é um elemento que se oxida com rapidez. No chá da casca de cebola houve dois tons de marrom devido à qualidade da casca (cebola nova, casca escura; cebola madura, casca clara).

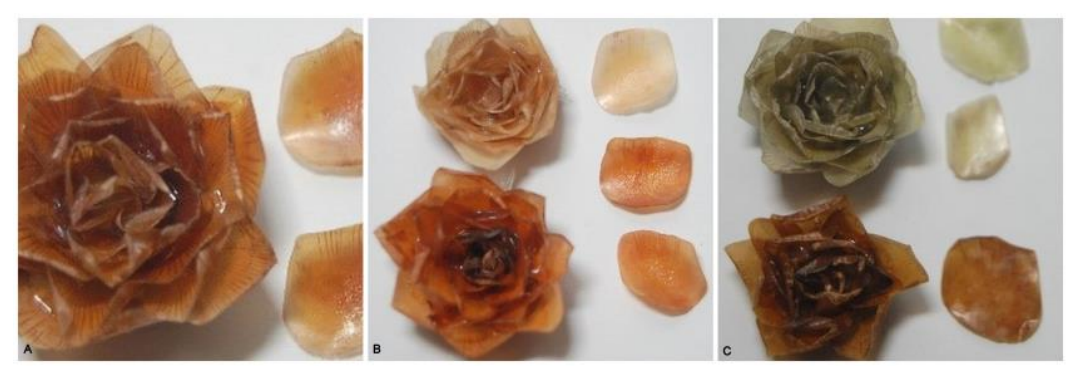

Figura 4): Resultado das flores de escama com corantes naturais. a) Sene; b)cebola e c)chá verde. Foto: Mariana Veiga. 
As escamas tingidas apresentaram aspecto homogêneo, diferenciando a cor através do uso de cada diferente vegetal e também houve a fixação adequada da cor na peça. Após testes de solubilidade, verificou-se que o tingimento não dilui, consistindo assim uma metodologia perfeitamente adequada a coloração das escamas de peixes.

\section{DESENVOLVIMENTO DA MARCA}

Marca é a soma intangível dos atributos de um produto; seu nome, embalagem e preço, sua história, reputação e a maneira como ele é promovido. A marca é também definida pelas impressões dos consumidores sobre as pessoas que a usam; assim como pela sua própria experiência pessoal (DAVID OGILV apud STRUNCK, 2001).

O processo criativo é uma etapa mais livre onde o papel do design como colaborador no desenvolvimento da atividade artesanal, segundo Aloísio Magalhães que:

(...) via a produção de bens como criação, e tinha profunda consciência da importância do processo criativo para a qualidade do produto. Interferir nesse processo sem tolher ou desviar sua trajetória, aprimorá-lo e enriquecê-lo com referências significativas tanto para o produtor como para o público, não era um desafio apenas para o artista, o designer, o planejador e o agente cultural, mas também, ainda que de forma inconsciente, para o artesão e o artista popular. (Taborda, Leite, 2003, p.234).

A fase de criação sobre a logomarca para o projeto ComuniArte envolveu a idéia de apresentar uma identificação simples, direta e objetiva que englobasse todas as comunidades no qual tem sua atuação (Figura 5). Esta marca representa o projeto no âmbito da UFRPE e de seus participantes. A partir da Comuniarte o projeto foi apresentado às comunidades pesqueiras. 
Comuniarte $=$ Comuni $($ comunidades $)+$ Arte (artesanato).

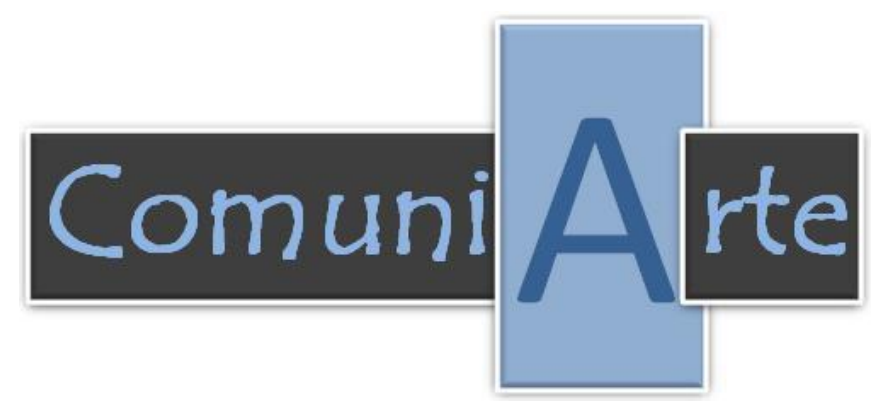

Figura 5): $1^{\circ}$ logomarca utilizada pelo projeto.

Para a criação da marca, determinou-se que a imagem deveria atender requisitos necessários que pudessem suscitar no público uma determinada opinião de reconhecimento, diferenciação, valorização ou proximidade afetiva com o artesanato (RIBEIRO, 2011). A marca é que melhor representa o negócio, em sendo base para todos os demais documentos impressos como: cartão de visita, etiquetas, folder, sacolas, adesivos, etc.

Vale ressaltar que é muito comum nesse segmento artesanal, o Industrianato, a criação de outras linhas com novos produtos, neste caso, pode ser definida identidades diferentes para cada linha, mas é recomendável que esses possam comungar dos mesmos propósitos, terem unidade. Caso não haja unidade é sempre importante que o processo seja revisto (STRUNCK, 2001). Após a criação da marca e confecção do material, o cartão de visita e folder foram os mais utilizados para divulgação do trabalho realizado no projeto ComuniArte e sendo um instrumento importante para divulgação em feiras, congressos, eventos entre outros. As propostas da logomarca durante a fase de criação foram determinadas pelos discentes que compõem o projeto e que sofreram adaptações necessárias para chegar a um resultado satisfatório. Foram cerca de 4 meses de trabalho, desde a escolha do nome a confecção da logomarca, cores e desenho, sempre em consenso através de votação dos membros quando haviam divergências entre as etapas. (Figura 6). 


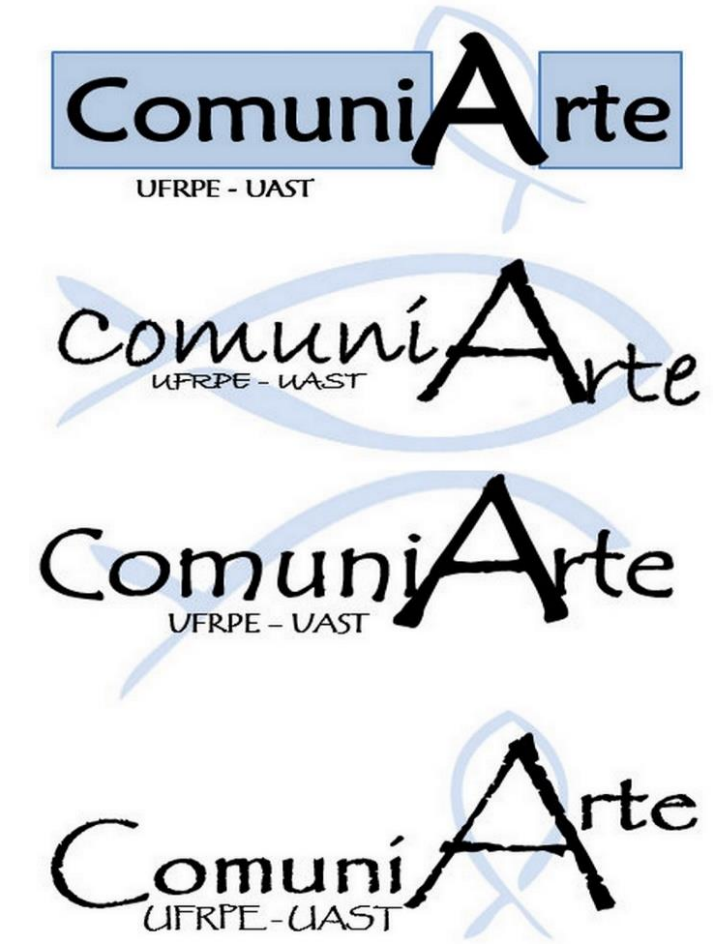

Figura 6): Fases de criação da marca para o projeto.

As marcas acima não foram selecionadas por apresentarem uma imagem com elevada informação. Sendo assim, optou-se por uma marca de fácil memorização pelo público e remetendo a ideia do aproveitamento da escama de peixe através da silhueta de um peixe (Figura 7). As cores são neutras, a fonte é de fácil visualização e fixação da imagem, com clareza da informação e significado do nome ComuniArte, que quer dizer: Comuni (comunidade) Arte (artesanato) e o peixe remete ao pescado em si. Após a aprovação pela equipe, a marca foi vetorizada e enviada a gráfica para confecção de adesivos, folders, panfletos e adesivagem da lojinha que serve de demonstração as comunidades e é utilizada em diversos eventos, na distribuição e vendas de peças artesanais. 


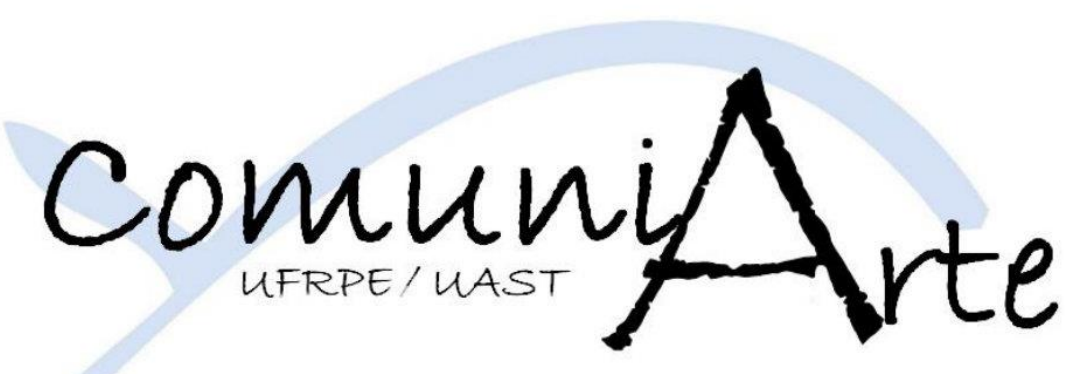

Figura 7): Marca escolhida para o projeto ComuniArte.

Após a definição da marca seguem os resultados do panfleto (Figura 8) e cartão de visita (Figura 9). Para o panfleto, como se trata de um único projeto, foram englobadas as informações das duas unidades acadêmicas (UFRPE - Serra Talhada e UFRPE - Sede). Na produção de cartão visita, houve a separação das informações como e-mail e telefone para contato por se tratarem de comunidades distintas. Ambos servem para distribuição e divulgação do projeto e da marca.

O processo de criação da marca ComuniArte constituiu a identidade do projeto, que hoje vem sendo conhecido no âmbito acadêmico e proporcionando a criação de Marca Coletiva: utilizada para distinguir produtos ou serviços dos membros de uma associação (OMPI, 2003), que proporcionará as comunidades que utilizem suas marcas, relacionando-as ao grupo e local específico ao seu trabalho artesanal. 

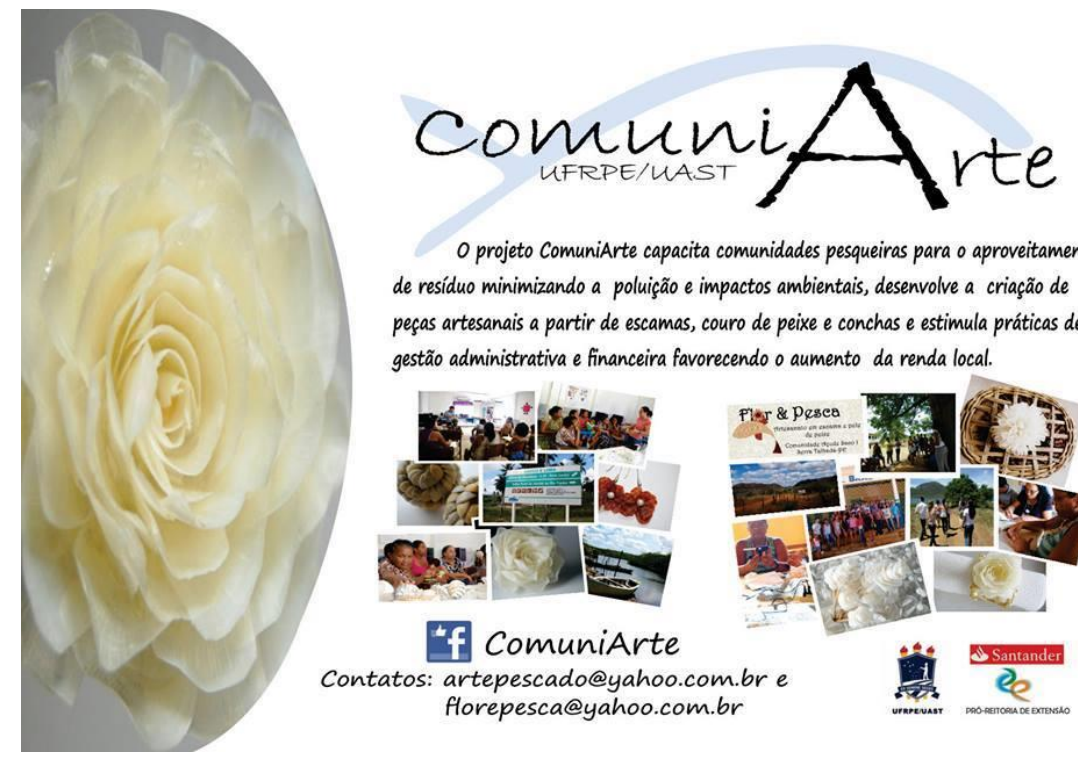

0 projeto ComuniArte capacita comunidades pesqueiras para o aproveitamento de resíduo minimizando a poluição e impactos ambientais, desenvolve a criação de pegas artesanais a partir de escamas, couro de peixe e conchas e estimula práticas de gestão administrativa e financeira favorecendo o aumento da renda local.

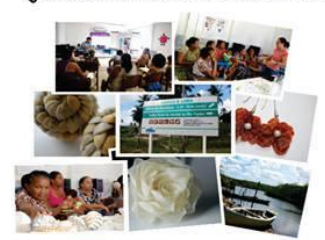

F ComuniArte Contatos: artepescado@yahoo.com.bre florepesca@yahoo.com.br
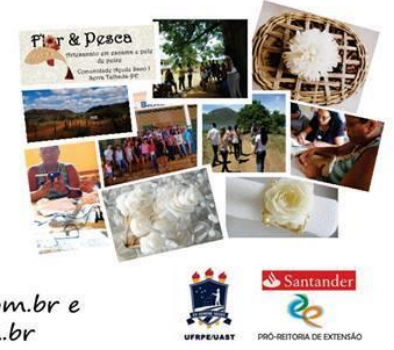

Figura 8): Resultado final do panfleto.

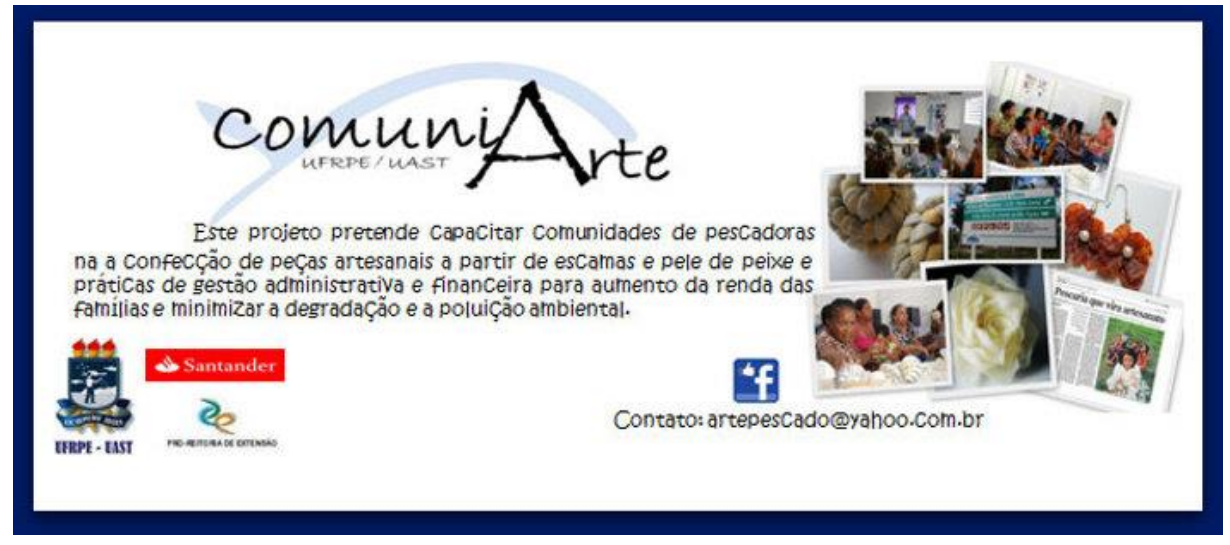

Figura 9): Cartão de visita.

A comunidade de Serra Talhada apresentou a marca "Flor \& Pesca" (Figuras 10 e 11) e o cartão de visita acrescentando características da atividade na confecção das flores de escama. Na comunidade do Porto Jatobá, a marca "Maré e Arte" já existia e a comunidade optou por continuar com o seu uso, não descaracterizando esta identidade mais antiga do local, que hoje engloba trabalhos com escamas. Na comunidade de Barra de Sirinhaém a marca está em desenvolvimento. 


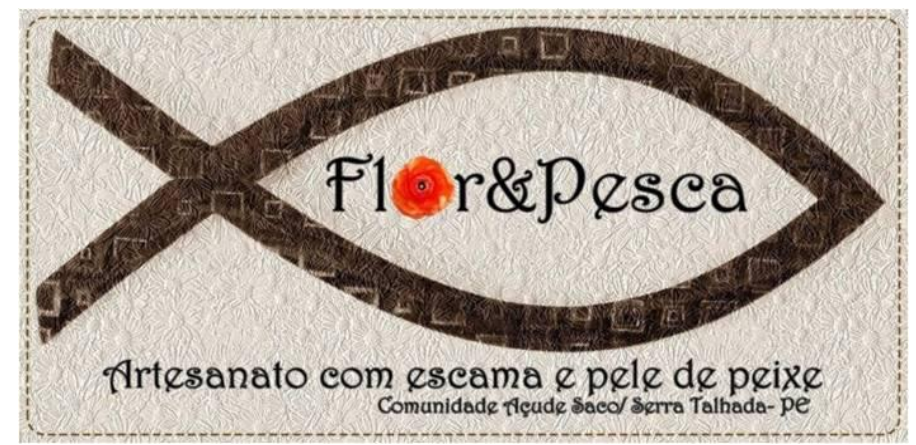

Figura 10): $1^{\mathrm{o}}$ cartão de visita realizado pela equipe de Serra Talhada.

Fonte: Equipe Flor\&Pesca.

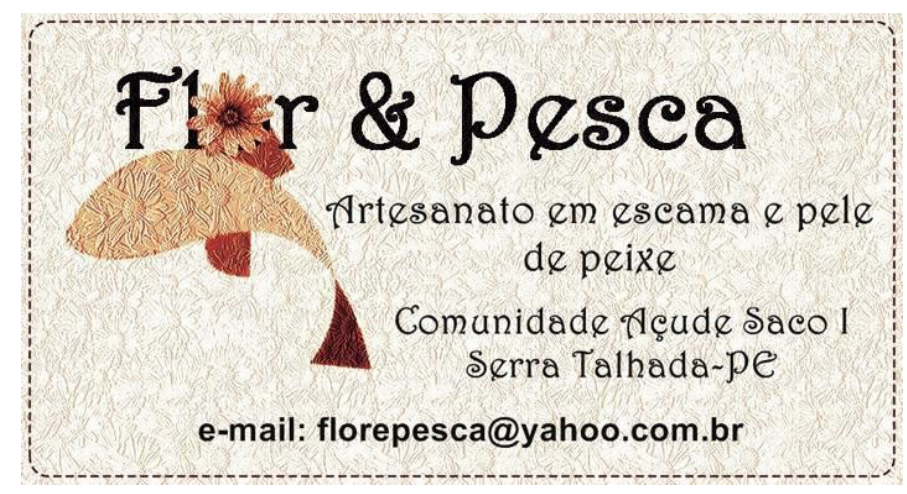

Figura 11): Resultado final do cartão de visita votados como padrão para uso em Serra Talhada. Fonte: Equipe Flor\&Pesca.

\section{CONCLUSÕES}

A técnica de aplicação de corantes naturais foi satisfatória, de baixo custo e fácil metodologia, deixando as escamas com aparência natural e possibilitando o não descarte das escamas no ambiente.

O trabalho realizado com as comunidades gerou uma perspectiva no aumento de renda, despertou interesse para criação de peças decorativas e novos modelos de bijuterias incluindo as peças tingidas com corantes naturais.

Em relação aos tipos de escamas, para utilização em artesanato pode-se aproveitar todos os tamanhos e diversos tipos (de acordo com a variedade do peixe). 
A marca Comuniarte possibilitou uma maior divulgação do projeto no ambiente acadêmico da UFRPE, e em outros estados como exemplo: São Paulo e Curitiba onde a procura por escama é elevada, e nos países como Argentina, México e Portugal.

Com a unificação de informações sobre as comunidades trabalhadas na rede social, viabilizou-se a divulgação da Flor\&Pesca para venda de peças e demonstrando assim as características de cada região.

Atualmente, as comunidades pesqueiras aceitam a troca de ideias ao longo da oficina de capacitação e sendo assim, contribuindo com atuação do Engenheiro de Pesca, Economistas Domésticas, Biólogos e Designs os trabalhos de extensão rural pesqueira visando a sustentabilidade ambiental.

Em parceria com as comunidades pesqueiras, pode-se realizar trabalhos futuros com outras espécies de peixes marinhos ou dulciaquícolas auxiliando na geração de renda e inserção social.

\section{REFERÊNCIAS BIBLIOGRÁFICAS}

ASSOCIAÇÃO BRASILEIRA DE NORMAS TÉCNICAS. NBR 10.004: Resíduos sólidos Classificação. Rio de Janeiro, 2004.

BENTO, D. M, BEMVENUTI, M. A. Os peixes de água doce da pesca artesanal no sul da Lagoa dos Patos, RS. Caderno de Ecologia Aquática. Universidade Federal do Pampa Unipampa, Bagé, v.3, n. 2, p 33-41. 2008

DIAS-NETO, J.; DORNELlES, L. C. C. Diagnóstico da pesca marítima do Brasil. Coleção Meio Ambiente. Série Estudos Pesca, 20. Ibama, Brasília. p165. 1996

MACHADO, Z. L. Tecnologia de recursos pesqueiros. Recife: Sudene. 277p.1984.

MACHADO, M. P. Responsabilidade Social Empresarial: Uma inserção do Serviço Social, Universidade Federal de Santa Catarina, Centro sócio econômico, Departamento de serviço social, Florianópolis, p 05-64, 2003. 
MARTINS, R. F. F. A gestão de design como uma Estratégia organizacional - um modelo de integração, Tese (Doutorado em Engenharia de Produção) - Programa de Pós- Graduação em Engenharia de Produção, UFSC, p. 205. 2004.

MELO, K. S. G. Extração e uso de corantes vegetais da Amazônia no tingimento do couro de Matrinxã (Brycon amazonicu \& Agassiz, 1819). 2 f. Dissertação - Universidade Federal do Amazonas, Manaus. p. 01-05, 2007.

MILlANI, T. J. Subsídios à Avaliação do Ciclo de Vida do pescado: avaliação ambiental das atividades de piscicultura e pesque-pague, estudo de caso na bacia hidrográfica do rio Mogi-Guaçu. p. 10-21, 2007.

PETRERE JR, M. Synthesis on fisheries in large tropical reservoirs in South America. Documento de consultoria preparado para a FAO/Roma, In: Simpósio Regional sobre Manejo de la Pesca en Embalses en America Latina, Havana, Cuba, p.04-06. Outubro de 1994.

SOUZA, M. L. R. et al. Análises da pele de três espécies de peixes: histologia, morfometria e testes de resistência. Revista Brasileira de Zootecnia, v. 32, n. 6. p. 1551$1559,2003$.

STRUNCK, G. L. T. L. Como criar identidades visuais para marcas de sucesso: guia sobre o marketing das marcas e como representar graficamente os seus valores. Rio de Janeiro: Rio Books, 2004.

SANTOS, G; et al. Beneficiamento de escamas de pescado do Mercado de São José, Recife-Pernambuco. In: AQUACIENCIA, Palmas. Anais... Palmas: UFRPE, p. 01.2012.

SEBRAE. Diagnóstico dos Resíduos da Pesca e Aquicultura do Espírito Santo. Brasil: Serviço Brasileiro de Apoio às Micro e Pequenas Empresas, p. 16-19.2010.

SOUZA, M. P. Instrumentos de gestão ambiental: Fundamentos e práticas. São Carlos: Ed. Riani Costa. 2000. 
TABORDA, F., LEITE, J. S. A herança do olhar- O design de Aloisio Magalhães. Rio de Janeiro, RJ: Arteviva Produção Cultural Ltda., 2003.

VIDOTTI, R.M.; GONÇALVES, G.S. Produção e caracterização de silagem, farinha e óleo de tilápia e sua utilização na alimentação animal. São Paulo, 2006. Disponível em: <ftp://ftp.sp.gov.br/ftppesca/producao_caracterizacao.dpf>. Acesso em: 17 janeiro 2014. 